\title{
Research and Application of PV (photovoltaic) Generation to Electric Motor System Based on Multi-converter Technology
}

\author{
Yuanzhuo Du, Tieyan Zhang, Yan Zhao and Qianzhi Shao \\ Shenyang Institute of Engineering, Shenyang, China \\ du_yz1122@163.com
}

\begin{abstract}
With development of society, people are aware of the crisis of energy shortage and importance of machine. In this paper, a new brand technology called multi-converter is proposed to apply in motor, which promotes PV industry. First, function and structure of $P V$ generation to electric motor is proposed, which covers five parts of key technology. Second, both function of solar energy controller and charge and discharge controller are analyzed. Then, bi-directional converter, the most important part is analyzed in this paper. At last, a control strategy is proposed according to the above to guarantee the system run normally. This paper also analysis power flow of the system. In the combination with the system of electric motor, this technology will go longer in future.
\end{abstract}

Keywords: solar, multi-converter, electric motor, power flow

\section{Introduction}

With progress of the science and technology, power demand is more and more strong to people. Many problems such as market, energy, technology and the power need to be resolved. As we all know, energy crisis has puzzled us till now many times. The shortage of primary energy such as petroleum, power resource and fossil energy not only affect residents' quality of life directly, but also caused social economic recession. The power crisis of California in history gives a warning to us. Either the failure of regulations of the power or the shortage of public supply caused the crisis. This crisis is worthy of learning a lesson, we should optimize the resource allocation continuously, adapt the market requirements, compatible with distributed generation to cope with the crisis around us.

The $12^{\text {th }}$ Five-Year Plan of Development of Renewable Energy issued by Chinese government pointed that accelerating PV technological advances, promoting multi-usage of solar, achieve PV generation in the way of self-demand-self-supply. Based on PV system, this paper summarizes multi-converter applied to electric motor, which power flow to multi-directional. A control strategy is proposed. It makes using solar energy for the first grade and energy flow to multi-directional come true.

\section{Function and Structure of PV Generation to Motor System}

Grid transform AC (alternating current) into DC (direct current) with AC/DC for battery directly. Solar cell collecting power connects with battery by controller. Multiconverter system is shown in Figure 1 Solar energy is used to supply to motor in first grade, then the grid power is ready for motor in second grade, the battery will be used in third grade. The controller combining among PV generation, grid and battery can ensure safety power supply. It also can bring remaining capacity generated by PV to grid through multi-converter system. Solar energy is still used in advance and bring power to motor directly, when battery need no power. Motor control power-driven and brake system supplied by grid when solar energy is short. When motor braking, energy will flow to grid through converter. 


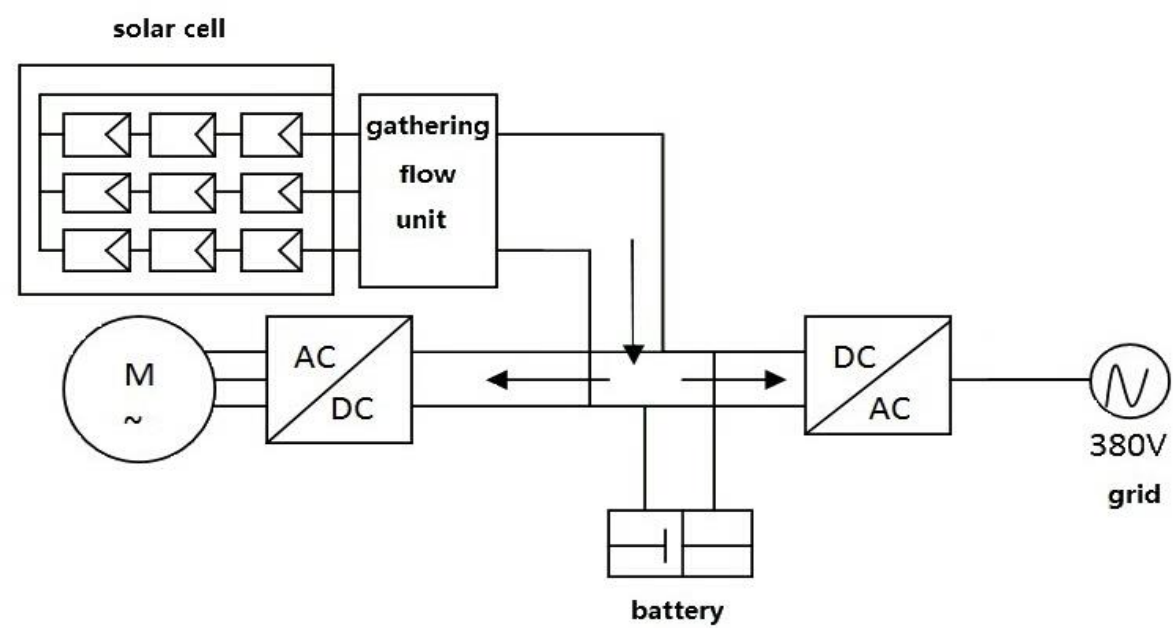

Figure 1. Structure of the System of Multi-Converter

\subsection{Principle of Solar Energy Controller}

Solar energy controller is widely used in the system of PV, and also plays an important role in the system of PV. It coordinates work among solar cell, battery and load. Collecting signals, protecting and controlling circuit, solar energy controller can work safely and effectively [1-2]. Principle of solar energy controller is shown in Figure 2.

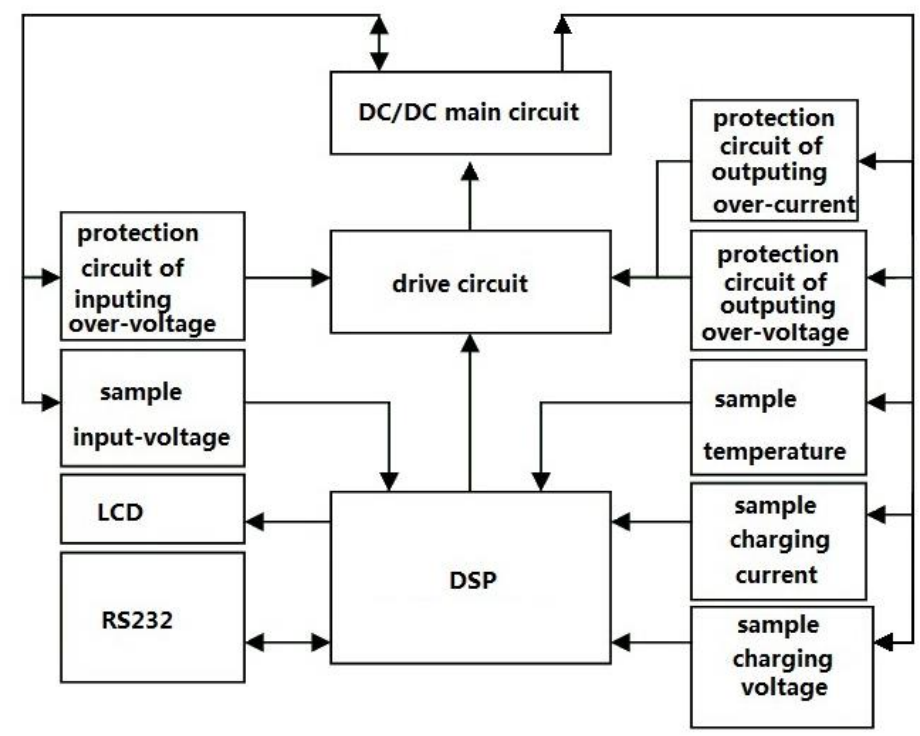

Figure 2. Principle of Solar Energy Controller

\subsection{Direct-driven of $P V$}

First, traditional way is to concentrate flow. Then, through grid-connected inverter, electricity invert three times to motor. Direct-Driven system brings solar energy to DC bus of converter directly. Energy use ratio is high to $99 \%$, which enhancing 6\%-8\%. That saves energy of grid-power-supply and dissipation of AC/DC. 


\subsection{Technology of Multi-Converter}

To apply multi-converter is to set up a model that exchange energy among PV system, motor, battery and grid. To install bi-directional converter chip in the node is to make power flow to 2 sides at room of DC-side. The system can switch many kinds of operation pattern (see 4.2) in real time that is less than $10 \mathrm{~ms}$. That can make the system steady running however energy changes. PV supply power to load and battery first, the rest of power will flow to grid. If PV cannot supply power enough, power will flow from grid to load and battery. To charge or discharge, power will flow from battery to other grades or from one-side to battery i.e. flow bi-directionally. Power will flow back to battery when motor is on braking state, and power will flow to grid if battery is full. The principle of multi-converter is shown in Figure 3.

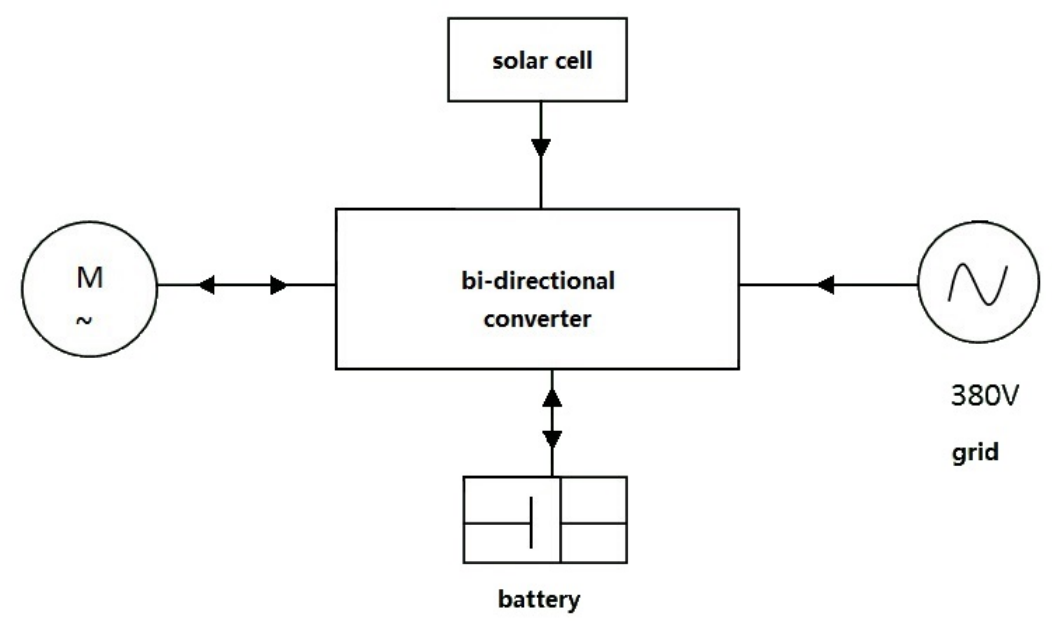

Figure 3. The Principle of Multi-Converter

\subsection{Maximum Power Point Tracing}

In PV system, use ratio of solar cell depends on internal structure of battery and other factors such as irradiance, load and temperature etc. Solar cell can run at a different and sole point named MMP (Maximum Power Point) in variety of external conditions. Therefore, technology of finding the maximum power point named MPPT (Maximum Power Point Tracing) for PV system. In theory, solar cell output maximum power when output impedance equals load impedance. Control stabilization of MPPT is higher. PV system will trace the MMP smoothly when it is running. It is independent of characteristic and parameters of solar cell [3-5].

\subsection{Motor Work on Four-Quadrant}

Motor need run and brake frequently in practice. Motor has 4 motion states that forward-running, back-braking, reverse-braking and reverse-running. $\mathrm{X}$ axis expresses motor speed, forward-direction expresses forward-running, another direction of $\mathrm{x}$ axis expresses reverse-running. $\mathrm{Y}$ axis expresses electromagnetic torque of motor, forwarddirection of $\mathrm{y}$ axis expresses positive electromagnetic torque and another direction expresses negative torque. In the first quadrant, motor is normal transfer in motoring status absorbing power from system. In the second quadrant, motor is reverse transfer in generating status transporting power to grid. In the third quadrant, motor is reverse transfer in motoring status absorbing power from system. In the $4^{\text {th }}$ quadrant, motor is normal transfer in generating status transporting power to grid. Demand of motoring- 
state-power and generating-state-power is right opposite. Motoring state is running when generating state stops. When motoring state stops, generating state works releasing power to grid without delaying. That is power flowing bi-directionally.

\section{Principle and Analysis}

\subsection{Main Circuit DC/DC of Solar Energy Controller}

Solar energy that is collected by PV-array uses buffer circuit into soft-switching environment, and charge to battery. Figure 4 shows ZSC-PWM-BOOST circuit. So-called $\mathrm{ZSC}$ environment is turning on and turning off with zero-current.

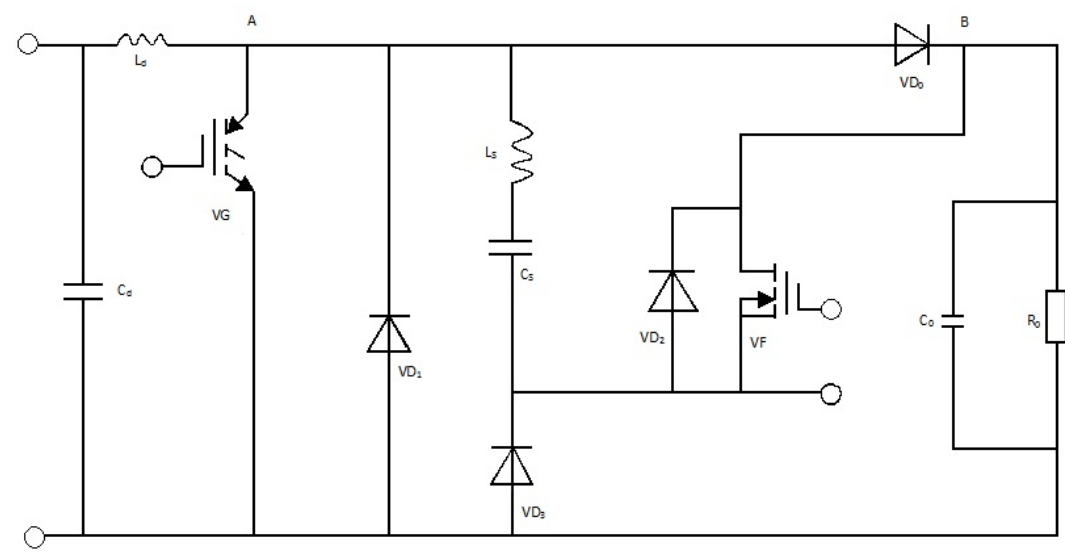

Figure 4. ZSC-PWM-BOOST Topology

As the buffer circuit beyond bi-directional converter, it does not change stability of main circuit unless changing status of device in main circuit.

Necessary condition that circuit has is:

$$
I_{C S m}>I_{d m}
$$

Where $I_{C S m}$ is the peak of current in $L_{S} C_{S}$ resonant circuit, $I_{d m}$ is maximum load current.

$$
\frac{U_{0}-U_{C 1}}{Z_{S}}=K I_{d m}
$$

In which $K$ is coefficient, $K \in(1.5,2)$.

To shorten the converter process, resonant period of $L_{S} C_{S}$ circuit:

$$
T_{r}=2 \pi \sqrt{L_{S} C_{S}}=\frac{T_{C}}{10}
$$

Where $T_{c}$ is switch cycle of main circuit.

\subsection{The Charge and Discharge Controller}

The charge and discharge controller is the key of the charge-control system, which will control both power switch and charging and discharging of battery. At the same time, it will display charging condition such as charging time, charging condition, charging current and voltage, temperature, etc.

1. Sampling circuit

(1) Current-sampling circuit 
Input current of battery is the most important part of charging-control. Activationcharging and rapid-charging with high current are both controlled in constant current charging in the system. Checking battery charging current with Holzer current sensor, five points to realize the current detection is the feature of Holzer current sensor i.e. the measuring circuit need not access detection circuit that will realize current detection. They rely on magnetic coupling. Therefore, detection circuit of input and output circuit is complete isolation. The principle of Holzer current sensors based on Holzer effect, the magnetic field of using the current generated by electrified wire is directly proportional to flow through the wire. The size of the current is detected indirectly through core aggregation induction to Holzer devices. Outputting current from a current sensor into the perforated core, current sensor sends scaling. The current signal is converted into a voltage signal I, and then the voltage signal through the RC filter into ADC of AVR micro controller analog to digital conversion.

(2) Battery voltage-sampling circuit

Battery voltage react the capacity state of battery, and system of charging control side is judged according to the battery voltage. The battery voltage is related to modeswitching of charging system. If the system is detected that the battery is in discharging state when charging in initial time i.e. when battery voltage is lower than the minimum threshold, the charge and discharge controller need to be activation charged with small current for battery, making battery voltage restore to acceptable charging state. Switching between two different charging modes is related to battery voltage in charging. Therefore, it is very important to detect battery voltage. Circuit of the battery voltage is sampled by the resistor divider, sending into $\mathrm{ADC} 1$ through $\mathrm{RC}$ low pass-filter.

(3) Input voltage-sampling circuit

Because of the limit of sampling scope of ADC in AVR micro controller, it can sample input voltage divider, which send into ADC0 through diode RC low pass-filter after conditioning, according to resistor divider that is sampled by input voltage after conditioning. By controlling the input voltage whether meet the sampling value, it can protect the battery security charging.

\section{(4) Temperature sampling circuit}

Because of polarization phenomenon, battery will have a certain temperature in charging. If temperature is too high, it will affect charging efficiency directly, and damage to battery to a great extent, thus temperature is crucial information in charging. Over charge and floating charge voltage is compensated to temperature according to battery in the system, for setting of charging voltage and floating voltage of battery reasonably. The temperature sensor used in China is the thermal resistance at present. The temperature sensor is a nonlinear sensor, it must use compensation circuit, and therefore, the circuit is complex with large volume. Temperature sensor send into sampling input in ADC3 of AVR micro controller through diode and a low pass filter in charging system. Over charge and floating charge set in chip is detected according to battery temperature in the process.

\section{Protecting circuit}

Over-current and overvoltage of battery and to protect the system is to be prevented by protecting input voltage of battery, charging voltage and charging current in hardware mode.

\section{Driving circuit}

Isolating and amplifying the signal of charging control circuit, control of the switch will control higher voltage by microprocessor.

4. Control module in charging 
According to the feature of battery, the progress of charging is be analyzed. That includes 4 parts. They are activation charge, fast charge in high current, overcharge and floating charge. Charging method for multi-mode can control over charge and floating charge state to maintain advantage of battery power with constant current charging and constant voltage charging which is quick and safe, compensating battery power timely. Charging condition can be monitored by the control strategy in real time, and charging to battery in predetermined scheme. Analyzing and judging of charge state of battery, selecting appropriate charge modes, activation charge can activate substances in battery which is over discharging effectively to avoid damage to battery with fast charge in high current. Fast charge in high current could supplementary power to battery efficiently. Over charge could make battery full, floating charge could supplementary power that loss by discharging of battery-self at last, to perfect charging. Procedures of control module in charging are shown in Figure 5.

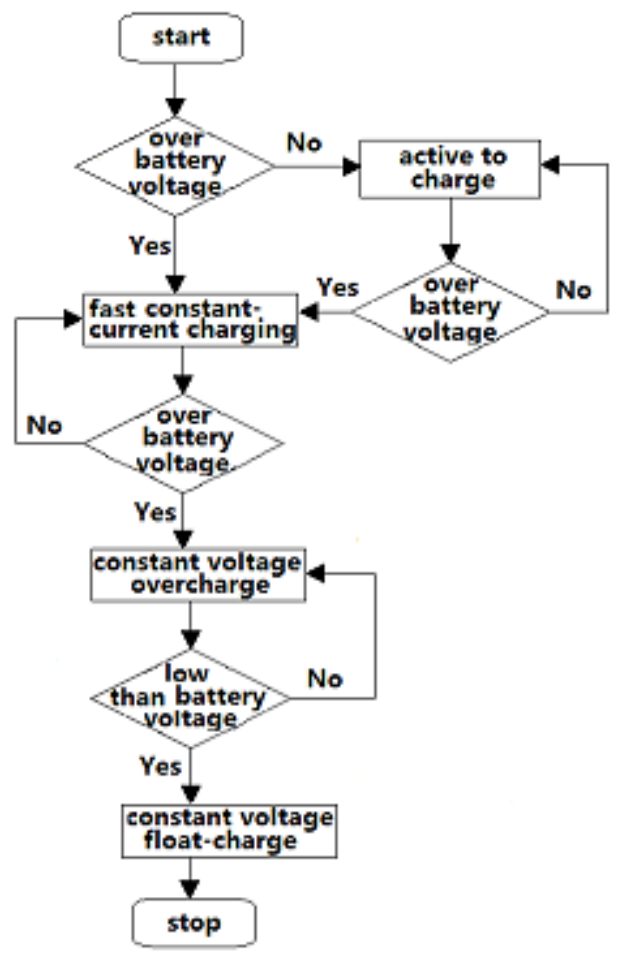

Figure 5. Procedures of Control Module in Charging

\subsection{Bi-directional Converter}

Key device of multi-converter is bi-directional converter. Solar energy flow to load first by inverter, grid bring power to load if solar cell cannot supply power enough. Grid supply AC to load and battery through three-phase inverter and rectifier. Power of braking will flow to grid-side and battery through rectifying of load-side. Therefore, that can achieve two-side invert-and-rectify, topology of bi-directional converter is shown in Figure 6. Principle of grid-side is the same as the above case.

Bi-directional converter function:

(1) DC power generated by PV charge battery with solar energy controller.

$\mathrm{PV} \Rightarrow$ Battery $\Rightarrow$ Bi-directional inverter $\Rightarrow$ Motor

(2) Grid charge battery in rectifying state by bi-directional converter. When generating excess power, PV transports power to grid in inverter state by bi-directional converter. Grid $\Leftarrow \mathrm{PV} \Rightarrow$ Bi-directional converter $\Rightarrow$ Battery $\Rightarrow$ Bi-directional inverter $\Rightarrow$ Motor 
(1) When motor braking in generating state, power from motor charge battery in rectifying state by bi-directional inverter, at the same time, power from motor flow back to grid.

Motor $\Rightarrow$ Bi-directional inverter $\Rightarrow$ Battery

(2) Battery has the function of collecting grid power and solar energy. If there is no sun light and electric dose not working, battery provide energy to the load.

Battery $\Rightarrow$ Bi-directional inverter $\Rightarrow$ Electric motor

The flow of system exchange and transmission is as follows:

Grid $\Leftrightarrow$ Bi-directional converter $\Leftrightarrow$ Battery $\Leftarrow$ Solar energy controller $\Leftarrow$ Solar cell

Motor $\Leftrightarrow$ Bi-directional inverter $\Leftrightarrow$ Battery

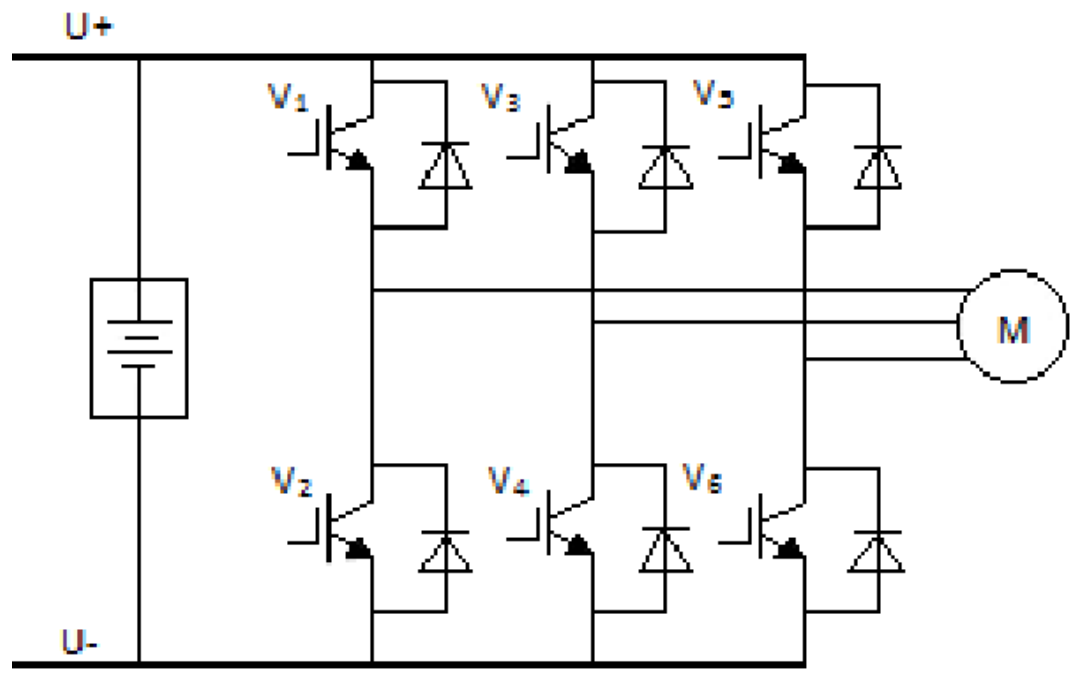

Figure 6. Topology of Bi-Directional Converter

Using three-phase bridge PWM inverter as an example, input current of AC-side is sine wave. Power factor can be controlled. The topology is fit for PWM rectifying and inverting situation at which the power could flow in two directions with fast dynamic response [6-10]. Such as U-phase, when $u_{r U}>u_{c}$, if giving the upper arm of bridge $\mathrm{V}_{1}$ turnon signal and the lower arm of bridge $\mathrm{V}_{4}$ turn-off signal, $u_{N}=u / 2$. When $u_{r U}<u_{c}$, if giving $\mathrm{V}_{4}$ turn-on signal and $\mathrm{V}_{1}$ turn-off signal, $u_{N}=-u / 2$. Signal of $\mathrm{V}_{1}$ and $\mathrm{V}_{4}$ are complementary, where, $u_{u N}, u_{V N}$ and $u_{W N}$, have 2 types of level, which is $\pm u / 2$. When arm of bridge 1 and 6 turn on, $u_{U V}=U$. When arm of bridge 3 and 4 turn on, $u_{U V}=-U$. When arm of 1 and 3 or 4 and 6 turn on, $u_{U V}=0$.

\section{Control Strategy}

\subsection{Control System}

Control part need to collect current, voltage and temperature signal in grid-side and load-side respectively, to protect circuit through drive current and to give feedback return to control part. The part can also monitor situations about battery and display if the battery is full. That protects the system safety and reliably. Control part of multi-converter is shown in Figure 7.

(1) PV-array is used for energy conversion in system. They can output certain power according to factors of light intensity and temperature.

(2) DSP (Digital Signal Processing) will control both power switch and charging and discharging of battery. DSP collect voltage, temperature, charging current and charging 
voltage signal at grid-side, and communicate with RS232, display charging time, charging situation, current, voltage and temperature and some useful parameters.

(3) Drive circuit isolate and amplify the charging signal. Turning on switch will give protection to input voltage and charging voltage of battery. That will assure circuit safe to avoid over current and over voltage. Parameters of input and output will be fed back to drive circuit.

(4) Charging and discharging controller of battery is charged by constant current. It will show working status and control charging and discharging in a certain way. The controller will use low-activated current to return to full, if detecting voltage is less than a certain threshold in early stage. Because of polarization, temperature of battery will rise when charging. At the same time, it is necessary to monitor the temperature. The controller can improve working performance and lengthen service life.

(5) DC/DC plays an important role in the system. MPPT and DC/AC help to save DC/DC. Finding optimum point rapidly and accurately, tracing and guaranteeing MMP, to use solar power first.

(6) With no considering influence of weather and external environment, grid transfer $\mathrm{AC}$ to $\mathrm{DC}$ that is $12 \mathrm{~V}$, charging to battery directly, if battery is full and the rest of power can supply to sample circuit.

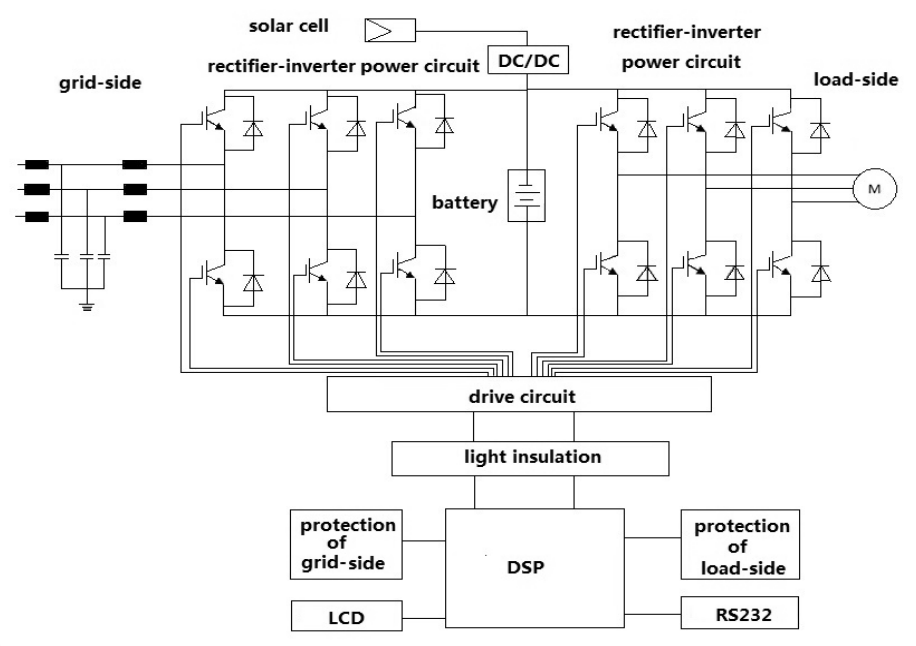

Figure 7. Control Part of Multi-Converter

\subsection{Control Strategy}

\subsubsection{Rectification and Inverter Analysis}

It is shown in Figure 7, AC from grid is sent to battery by rectifier circuit, DC from battery is sent to motor by inverter circuit. Battery is charged by PV that use for the first grade through DC/DC, and DC from battery is sent to motor by inverter circuit. When motor braking, power generated by motor charge to battery by rectifier circuit, the rest of power is sent from battery to grid by inverter circuit. When PV supply more power than motor consuming, PV send power to battery by DC/DC, DC generated by battery return the rest power to grid by inverter circuit.

1. Rectification mode analysis

Rectification and inverter part in grid side is shown by Figure 7 and grid voltage is symmetrical sine wave. 


$$
\left\{\begin{array}{c}
u_{A 0}=U_{N m} \sin \omega t \\
u_{B 0}=U_{N m} \sin \left(\omega t-\frac{2 \pi}{3}\right) \\
u_{C 0}=U_{N m}\left(\sin \omega t+\frac{2 \pi}{3}\right)
\end{array}\right.
$$

(1) Timing distribution of control signal

Each phase sinusoidal modulation signal is $u_{g a}, u_{g b}, u_{g c}$. The amplitude are all $U_{g m}$, the frequency is equal to the network frequency.

$$
\left\{\begin{array}{c}
u_{g a}=U_{g m} \sin (\omega t-\varphi) \\
u_{g b}=U_{g m} \sin \left(\omega t-\varphi-\frac{2 \pi}{3}\right) \\
u_{g c}=U_{g m} \sin \left(\omega t-\varphi+\frac{2 \pi}{3}\right)
\end{array}\right.
$$

Each phase sinusoidal modulation signal is lagging behind each phase voltage at an angle $\varphi$.

$$
\begin{aligned}
& \varphi=\arctan \frac{\omega L_{N}}{R_{N}} \\
& R_{N}=\frac{U_{A 0}}{I_{A 1}}
\end{aligned}
$$

$R_{N}$ is alternating current resistance. $U_{A 0}$ is RMS phase voltage in grid. $I_{A 1}$ is RMS of fundamental wave phase current. Carrier voltage is $u_{c}$, amplitude is $U_{c m}$, repetition frequency is $f_{c}$, modulation ratio is $m=U_{g m} / U_{c m}$, the frequency ratio is $\mathrm{K}=f_{c} / f$.

(2) Bridge lateral line voltage analysis

Such as a, b phase, bridge lateral line voltage is $u_{a b}=u_{a 0^{\prime}}-u_{b 0^{\prime}} \cdot u_{a 0^{\prime}}$ is voltage to a phase and output center $O^{\prime}$. $u_{b o^{\prime}}$ is voltage to $O^{\prime}$.

$$
\begin{aligned}
& u_{a 0^{\prime}}=\left\{\begin{array}{l}
\frac{U_{0}}{2} S_{1}^{0} \mid \\
-\frac{U_{0}}{2} S_{4}^{0}
\end{array}\right\} \\
& u_{b 0^{\prime}}=\left\{\begin{array}{c}
\frac{U_{0}}{2} S_{3}^{0} \mid \\
-\frac{U_{0}}{2} S_{6}^{0} \mid
\end{array}\right\}
\end{aligned}
$$

$S_{1} \sim S_{6}$ are three-phase bridge arms respectively. $S_{1}$ and $S_{4}$ are upper and lower bridge arms of a phase. And do on. When $S_{1}\left(\right.$ include $V T_{1}$ and $\left.V D_{1}\right)$ is break over, $u_{a 0^{\prime}}=\frac{U_{0}}{2}$, on the contrary, when $S_{4}\left(\right.$ include $V T_{4}$ and $\left.V D_{4}\right)$ is break over, $u_{a 0^{\prime}}=-\frac{U_{0}}{2}$, over two.

(3) Phase voltage in bridge side analysis 
Each phase voltage in bridge side is $u_{N 0}=\left.K_{N} U_{0}\right|_{N=a, b, c}$, among them, $K_{N}=\left.\left(S_{N}-\frac{S_{a}+S_{b}+S_{c}}{3}\right)\right|_{N=a, b, c}, S_{a}, S_{b}, S_{c}$ are switch function of each phase voltage respectively. $u_{a 01}$ and the modulated signal $u_{g a}$ of a phase are in the same phase.

$$
u_{a 01}=U_{a m} \sin (\omega t-\varphi)
$$

Where $U_{a m}$ is the amplitude of $u_{a 01}$.

2. Inverter mode analysis

Suppose carrier signal $u_{c}$ is triangular wave, amplitude is $U_{c m}$, repetition frequency is $f_{c}$, the modulated signals are $u_{g a}, u_{g b}$ and $u_{g c}$,

$$
\left\{\begin{array}{l}
u_{g a}=U_{g m} \sin \left(\omega t-\frac{\pi}{6}\right) \\
u_{g b}=U_{g m} \sin \left(\omega t-\frac{5 \pi}{6}\right) \\
u_{g c}=U_{g m} \sin \left(\omega t+\frac{\pi}{2}\right)
\end{array}\right.
$$

Where $U_{g m}$ is amplitude wave of modulated signal, $f$ is frequency of modulated signal.

Filter cut-off frequency is $f_{0}, f_{0}=\frac{f_{k}}{C h B_{0}} \cdot B_{0}=\ln \frac{U_{k i m}}{U_{k 0 m}}$, which $U_{k 0 m}$ and $U_{k i m}$ are amplitude of the lowest harmonic voltage of filter output and input respectively, $C h B_{0}=\frac{1}{2}\left(e^{B 0}+e^{-B 0}\right)$.

Filter circuit characteristic impedance is $Z_{0}$, can be expressed as

$$
Z_{0}=\sqrt{\frac{L_{0}}{C_{0}}}
$$

Relationship between $Z_{0}$ and $R_{0}$ is $Z_{0}=(0.5 \sim 0.8) R_{0}$.

\subsubsection{The Principle of System Control}

\section{Control system}

Three phase controlled rectifying circuit is taken as an example. Figure 8 shows structure of control system [11-15].

(1) Comparing a given $u_{d}^{*}$ signal and practical voltage $u_{d}$, and then send it to PI adjustor, PI output $i_{d}$ signal.

(a) If load current rose, capacitance $\mathrm{C}$ in DC-side discharge, $u_{d}$ fall and input for PI shows positive deviation, which make id rise and voltage $u_{d}$ in DC-side recover. In the final state, $u_{d}$ * equals to $u_{d}$, input for PI return to $0, i_{d}$ is corresponding to $\mathrm{AC}$ input current.

(b) If load current fell, controlled process is opposite.

(2) If rectifier turned to inverter, current of load-side is opposite, charging to capacitance $\mathrm{C}$, making $u_{d}$ rise, PI shows negative deviation, $i_{d}$ drop to negative, being into inverter. In the final state, input for PI return to 0 , output $i_{d}$ is negative, corresponding to current of inverter. 


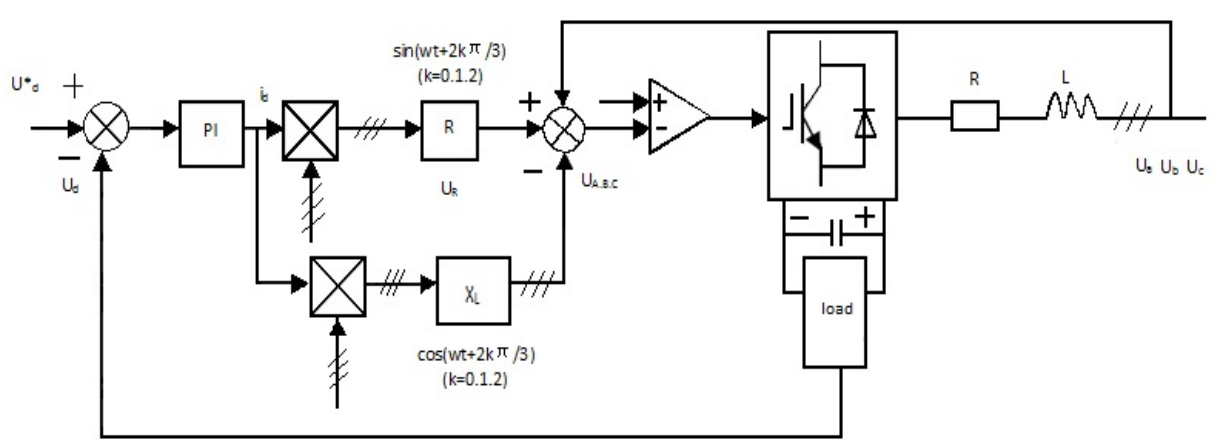

Figure 8. Structure of Control System

2. The dynamic performance of the system

According to Figure 9, suppose $W_{L}(s)$ is the output filter transfer function which contains a load resistor $R_{0}$ inside, $W_{I}(s)$ is the transfer function of inverter, $W_{k}(s)$ is the transfer function between error voltage $U_{e}(s)$ and modulation voltage $U_{g}(s)$. And $\beta(s)$ is the transfer function of feedback network.

$$
\begin{aligned}
& W_{L}(s)=\frac{1}{a^{2} s^{2}+b s+1} \\
& W_{I}(s)=\frac{U_{B 0}(s)}{U_{g}(s)}=K_{I} \\
& W_{k}(s)=\frac{U_{g}(s)}{U_{e}(s)}=K_{V}
\end{aligned}
$$

In the formula, $U_{B 0}$ is low frequency equivalent voltage in average output voltage of inverter bridge mode, $U_{g}$ is modulated signal, $U_{e}$ is error signal.

$$
\begin{aligned}
& U_{e}=U_{R}-U_{f} \\
& a=\sqrt{L_{0} C_{0}} \\
& b=\frac{Z_{0}}{2 R_{0}}, Z_{0}=\sqrt{\frac{L_{0}}{C_{0}}}
\end{aligned}
$$

Suppose input signal is $U_{R}(s)$, output signal is $U_{0}(s)$. Suppose $K_{I}$ is constant, closed loop transfer function of given signal $U_{R}(s)$ is $W_{R}(s)$, closed loop transfer function of disturbance quantity $U_{n}(s)$ is $W_{n}(s)$, therefore,

$$
\begin{aligned}
& W_{R}(s)=\frac{U_{0}(s)}{U_{R}(s)}=\frac{K_{S}}{1+K_{0}+b s+a^{2} s^{2}} \\
& W_{n}(s)=\frac{U_{0}(s)}{U_{n}(s)}=\frac{1}{1+K_{0}+b s+a^{2} s^{2}}
\end{aligned}
$$

In the formula, $K_{0}=\beta K_{V} K_{I}, K_{S}=K_{V} K_{I}=\frac{K_{0}}{\beta}$. 
Open loop transfer function of given signal and disturbance quantity by system is $W_{0 R}(s)=W_{0 N}(s)=\frac{K_{0}}{1+b s+a^{2} s^{2}}$.

Characteristic root is $S_{P 1.2}=-\frac{1}{2 R_{0} C_{0}} \pm \sqrt{\left(\frac{1}{L_{0} C_{0}}\right)-\left(\frac{1}{2 R_{0} C_{0}}\right)^{2}}$.

Thus, the dynamic performance is related to load, the lighter is the load, the worse the dynamic performance.

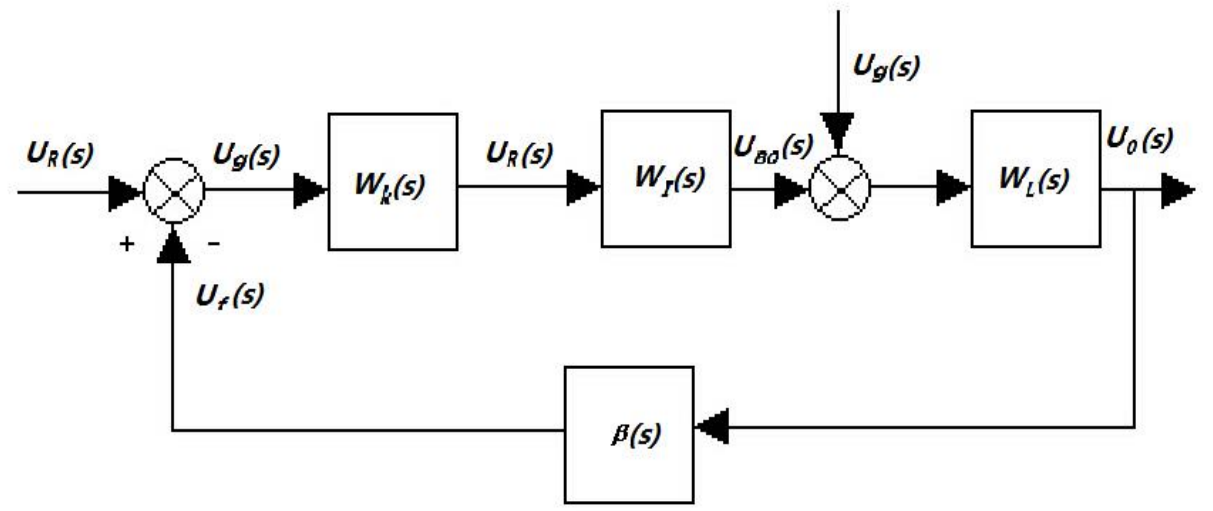

Figure 9. The Inverter Circuit Diagram of Voltage Feedback

\subsubsection{Module of Energy Flow}

Establish module of energy flow in multi-converter system according to Figure 7.

$$
P_{G}+P_{V}+P_{D}=P_{M}
$$

$P_{G}$ is power of releasing in power grid, $-P_{G}$ is power of absorbing in grid. $P_{V}$ is power of releasing in solar. $P_{D}$ is power of releasing in battery, $-P_{D}$ is power of absorbing in battery. $P_{M}$ is power consumed by motor, power of releasing by motor is $-P_{M}$ when motor is braking.

When motor is running, $P_{M}$ is constant, $P_{G}, P_{V}, P_{D}$ change to different numerical value has different condition.

1. $P_{M}>0$,

(1) $P_{V}>0$ and $P_{G} \neq 0$ : $P_{V}$ charge to $P_{D}, P_{D}$ send power to $P_{M}$ by inverter circuit.

(2) $P_{V}=0$ and $P_{G} \neq 0: P_{G}$ charge to $P_{D}$ through rectifier circuit, $P_{V}$ charge to $P_{D}$ by DC/DC, directional current from $P_{D}$ send into $P_{M}$ by inverter circuit.

(3) $P_{V}=0$ and $P_{G}=0: P_{D}$ send power to $P_{M}$ by inverter circuit directly.

2. $P_{M}<0$,

(1) $P_{V}>0$ and $P_{G} \neq 0: P_{V}$ send power to $P_{D}$ by DC/DC directly, at the same time $P_{M}$ by inverter circuit and $P_{V}$ send power to $P_{D}$ together, and then return back to $P_{G}$ by inverter circuit.

(2) $P_{V}=0$ and $P_{G} \neq 0: P_{M}$ send power to $P_{D}$ by rectifier circuit, and return power to $P_{G}$ by inverter circuit.

3. $P_{M}=0$,

$P_{V}>0$ and $P_{G} \neq 0: P_{V}$ send power to $P_{D}$ by DC/DC, and send power back to $P_{G}$ by inverter circuit.

\subsubsection{Five Models of Control System}

(1) PV power>power consumption 
a) If battery is not full, PV power will supply to load firstly, supply to battery secondly.

b) If battery is full, PV power will supply to load firstly, the rest power flow to grid.

(2) PV power<power consumption, PV power supply to load firstly

a) If battery is not full, grid power will supply to load and battery.

b) If battery is full, grid power will supply to load.

(3) PV power=power consumption

PV power supply to load, which realize self-demand-self-supply, supply no power to outside.

(4) $\mathrm{PV}$ power $=0$

a) Grid power supply to load and battery completely.

b) If grid-side do not work, battery will supply all power to load.

(5) When motor is braking

a) Power flow back to battery firstly through rectifier and inverter of load-side.

b) If battery is full, power will return back to grid.

\section{Conclusion}

Combination between solar cell and energy storage makes motor system reliably. Power flowing in two directions makes energy utilization rate going up. In this paper, multi-converter makes power flow come true. PV industry is broadly promoted. Using solar energy gathered to motor for the first grade. Power flows from PV system to motor through DC/DC. Power gathered charge battery for transfer to DC to motor. It can also flow back to grid when either power of load demand or power of battery is full. That makes power flow to multi-directional. Demand of traffic fields is rising up day by day. PV system and technology of multi-converter applied to the system of electric motor is fit for electric locomotive like train, steamer, etc. We can lay solar cell on the roof of train or on the part of deck, combining with grid, applying to motor it have had. The way is a prospective choice. Changing three-phase inverter to single-phase PWM rectifier, motor with smaller power can be used in that way. PV applied in motor system has a bright future. It becomes an environmental friendly way of traffic to protecting environment with technology of multi-converter.

\section{Acknowledgements}

This work is supported by National Nature Science Foundation of China under Grant 61304069, 61372195, 61371200 the Nature Science \& Foundation of Liaoning Province under Grant 2013020124, the Key Technologies R\&D Program of Liaoning Province under Grant 2011224006, 2012201010, the Key Project of Chinese Ministry of Education under Grant 212033, the Science and Technology Program of Shenyang under Grant F11264-1-70 and the Scientific Research Fund of Liaoning Provincial Education Department under Grant L2013494, L2012374.

\section{References}

[1] X. G. Wang, L. X. Zhao and Y. W. Lu, Industrial Instrument and Device of Automation”, vol. 1, no. 73, (2011).

[2] X. R. Su, Z. S. Wang and J. H. Ma, Mechanical \& Electrical Engineering Magazine, vol. 30, no. 1133, (2013).

[3] L. W. Zhang, J. W. Zhang and W. Tian. Applied Energy Technology, vol. 1, no. 4, (2010).

[4] M. G. Li, P. Y. Li and W. J. Xie, Industry and Mine Automation, vol. 39, no. 78, (2013).

[5] T. S. Zhang, G. H. Wang and Z. W. Jiao, Energy Conservation Technology, vol. 31, no. 175, (2013).

[6] B. Zhao, Q. G. Yu and L. W. Wang, Proceedings of the CSEE, vol. z1, no. 244, (2011).

[7] Y. B. Liu, X. Wang and Z. Q. Bo, Power System Protection and Control, vol. 5, no. 17, (2014).

[8] S. L. Lu, W. Y. Ju and Z. L. Jia, Power Electronics, vol. 47, no. 41, (2013).

[9] Y. Bao, J. C. Jiang and H. T. Zhang, Proceedings of the Chinese Society for Electrical Engineering, vol. 32, no. 50, (2012).

[10] L. Tang, C. B. Zeng and H. Miao, Power System Protection and Control, vol. 14, no. 13, (2013). 
[11] S. C. Wei, G. M. Zhang and B. J. Ji, Automation of Electric Power Systems, vol. 8, no. 91, (2014)

[12] Q. Yuan, X. M. Jin and G. H. Zeng, Chinese Journal of Power Sources, vol. 37, no. 1439, (2013).

[13] Z. Zeng, H. Yang and R. X. Zhao, Electric Power Automation Equipment, vol. 33, no. 56, (2013).

[14] G. R. Zhang, L. P. Zhou and L. Chen, Electrical Measurement \& Instrumentation, vol. 49, no. 41, (2012).

[15] S. C. Wei, G. M. Zhang and B. J. Ji, Modern Electric Power, vol. 30, no. 27, (2013).

\section{Authors}

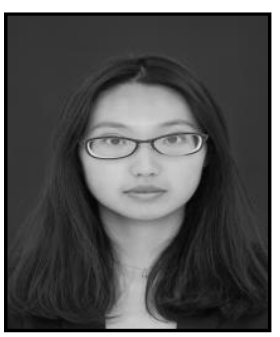

Yuanzhuo Du received the B.E. degree in School of Mechatronics Engineering from Shenyang Aerospace University, Liaoning, China in 2012.

She is currently working towards the Master in Electrical Engineering in Shenyang Institute of Engineering.

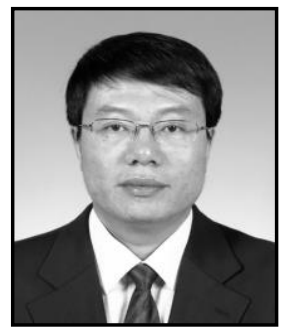

Tieyan Zhang was born in 1962. He received the Ph.D. degree in control theory and control engineering from Northeastern University, Shenyang, China, in 2007.

$\mathrm{He}$ is currently a professor and president of the Shenyang Institute of Engineering, Shenyang. His current research interests include fuzzy controls, fault diagnosis on electric power systems, and stability analysis on smart grids.

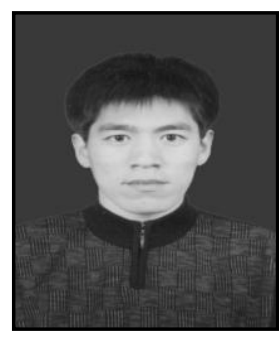

Yan Zhao received the $\mathrm{Ph} . \mathrm{D}$. degree in control engineering from Northeastern University, Shenyang, China, in 2008.

$\mathrm{He}$ is currently an associate professor with the School of Renewable Energy, Shenyang Institute of Engineering, Shenyang. His current research interests include fuzzy control, and intelligent control.

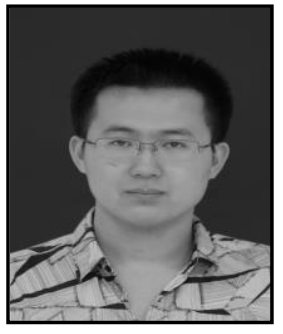

Qianzhi Shao received the B.E. degree in Energy and Power Engineering from Dalian University of Technology, Liaoning, China in 2012.

$\mathrm{He}$ is currently working towards the Master in Electrical Engineering in Shenyang Institute of Engineering. 